\title{
Effect of warmed ropivacaine solution on onset and duration of axillary block
}

\author{
Rippy Lee, Young Mi Kim, Eun Mi Choi, Young Ryong Choi, and Mi Hwa Chung \\ Department of Anesthesiology and Pain Medicine, Kangnam Sacred Heart Hospital, Hallym University College of Medicine, Seoul, Korea
}

Background: Bicarbonate, as an adjunct increasing the non-ionized form of local anesthetics, can reduce latency and prolong duration of regional nerve block. Warming of local anesthetics decreases pKa and also increases the non-ionized form of local anesthetics. We warmed ropivacaine to body temperature $\left(37^{\circ} \mathrm{C}\right)$ and evaluated the sensory block onset time, motor block onset time and analgesic duration of axillary block.

Methods: Patients were consecutively allocated to two groups of 22 patients each. Ropivacaine $150 \mathrm{mg}(30 \mathrm{ml})$ at $20^{\circ} \mathrm{C}$ (room temperature) and $150 \mathrm{mg}(30 \mathrm{ml})$ at $37^{\circ} \mathrm{C}$ (body temperature) was injected in group 1 and group 2, respectively. Sensory block and motor block was assessed every 5 minutes, for 30 minutes after injection. The duration of analgesia was recorded after operation.

Results: In group 2, the onset times of both sensory and motor block of the radial, ulnar, median and musculocutaneous nerves were significantly reduced, compared to group 1. Also, the number of blocked nerves was increased in group 2, within 30 minutes after injection. Analgesia lasted for 2 hours longer in group 2, compared to group 1, but the difference was not statistically significant $(\mathrm{P}>0.05)$.

Conclusions: Warming of ropivacaine to $37^{\circ} \mathrm{C}$ can reduce the onset time of both sensory and motor block, during axillary block. (Korean J Anesthesiol 2012; 62: 52-56)

Key Words: Axillary block, Onset time, pKa, Ropivacaine, Warming.

Received: March 14, 2011. Revised: 1st, April 29, 2011; 2nd, June 22, 2011. Accepted: July 11, 2011.

Corresponding author: Mi Hwa Chung, M.D., Department of Anesthesiology and Pain Medicine, Kangnam Sacred Heart Hospital, Hallym University College of Medicine, 948-1, Daerim 1-dong, Yeongdeungpo-gu, Seoul 150-950, Korea. Tel: 82-2-829-5230, Fax: 82-2-845-1571, E-mail: mhchung20@hallym.or.kr

(c) This is an open-access article distributed under the terms of the Creative Commons Attribution Non-Commercial License (http:// creativecommons.org/licenses/by-nc/3.0/), which permits unrestricted non-commercial use, distribution, and reproduction in any medium, provided the original work is properly cited. 


\section{Introduction}

In regional nerve blocks, the use of adjuncts along with local anesthetics can improve the anesthetic effect [1]. Epinephrine and bicarbonate are widely used as adjuncts for regional nerve blocks, because they reduce the onset time and prolong the duration of analgesia. Epinephrine makes local anesthetics last longer by reducing the adjacent blood flow and bicarbonate increases the non-ionized form by alkalinizing the local anesthetics [2].

Bupivacaine and ropivacaine are local anesthetics commonly used in regional nerve blocks. In particular, ropivacaine is known to have less toxicity to both cardiovascular and central nervous systems, compared to bupivacaine [3]. However, even the use of ropivacaine alone reduces the adjacent blood flow; thus, mixing ropivacaine with epinephrine does not have the effect of an adjunct. Furthermore, mixing ropivacaine with bicarbonate may reduce the bioavailability of ropivacaine by causing precipitation [4-7].

Warming of some local anesthetics, e.g. bupivacaine, reduces the pKa values and increases the non-ionized form; therefore, reduced onset time and increased duration can be anticipated in regional nerve blocks, similar to using bicarbonate as an adjunct, as previously reported [8-10].

Changes in the onset time of the sensory and motor block, as well as changes in the duration of analgesia have been recorded

Table 1. Demographic Data

\begin{tabular}{|c|c|c|}
\hline & Group 1 & Group 2 \\
\hline $\begin{array}{l}\text { Number of } \\
\text { patients (n) }\end{array}$ & 22 & 22 \\
\hline Age (yr) & $45.1 \pm 11.4$ & $38.3 \pm 15.3$ \\
\hline $\operatorname{Sex}(M / F)$ & $7 / 15$ & $13 / 9$ \\
\hline Height $(\mathrm{cm})$ & $161.1 \pm 9.3$ & $166.8 \pm 8.7$ \\
\hline Weight (kg) & $61.1 \pm 11.5$ & $64.9 \pm 10.1$ \\
\hline $\operatorname{BMI}\left(\mathrm{kg} / \mathrm{m}^{2}\right)$ & $23.4 \pm 2.7$ & $23.3 \pm 3.4$ \\
\hline ASA class $(1 / 2)$ & $17 / 5$ & $14 / 8$ \\
\hline \multirow[t]{11}{*}{ Surgery (n) } & Finger: 9 & Finger: 3 \\
\hline & - Mass: 3 & - Laceration: 1 \\
\hline & - Laceration: 3 & - Fracture: 2 \\
\hline & - Fracture: 3 & \\
\hline & Wrist: 11 & Wrist: 13 \\
\hline & - Mass: 2 & - Mass: 1 \\
\hline & - Carpal tunnel synd: 3 & - Laceration: 2 \\
\hline & - Fracture: 6 & $\begin{array}{l}\text { - Carpal tunnel syndrome: } 1 \\
\text { - Fracture: } 9\end{array}$ \\
\hline & Forearm: 2 & Forearm: 6 \\
\hline & - Mass: 1 & - Fracture: 6 \\
\hline & - Fracture: 1 & \\
\hline
\end{tabular}

Values are expressed as mean \pm SD or number of patients. Group 1: ropivacaine at room temperature $\left(20^{\circ} \mathrm{C}\right)$ was used as local anesthetic for axillary block. Group 2: ropivacaine warmed to the body temperature $\left(37^{\circ} \mathrm{C}\right)$ was used for axillary block. after warming ropivacaine to the temperature of $37^{\circ} \mathrm{C}$, when performing axillary nerve block.

\section{Materials and Methods}

The subjects of this study were 44 patients aged between 18 and 69 years, who underwent upper arm surgery and whose ASA class was 1 or 2 (Table 1). Prior to the study, the patients and their caregivers were given an explanation about this study and signed informed consent forms.Patients with coagulopathy or neurological disorder and those with BMI higher than 35 $\mathrm{kg} / \mathrm{m}^{2}$ were excluded from the study. The double blind design could not be used because the doctors had to directly touch and look at the drugs during the experiment.

For patients in Group 1, $30 \mathrm{ml}$ of $0.5 \%$ ropivacaine solution were prepared by mixing $20 \mathrm{ml}$ of $0.75 \%$ ropivacaine (Rocaine inj ${ }^{\circ}$, Reyon pharmaceuticals, Korea) with $10 \mathrm{ml}$ of normal saline, both stored for more than 24 hours in a cabinet in which the temperature was maintained at $20^{\circ} \mathrm{C}$; this mixture was used for the axillary nerve block. Before use, the equipment, syringes, and scalp vein needles used for anesthesia were stored in a room in which the temperature was maintained between 20 and $24^{\circ} \mathrm{C}$.

For patients in Group 2, $30 \mathrm{ml}$ of $0.5 \%$ ropivacaine solution was prepared by mixing $20 \mathrm{ml}$ of $0.75 \%$ ropivacaine with 10 $\mathrm{ml}$ of normal saline, both warmed up to $37^{\circ} \mathrm{C}$; this warmed mixture was used for the axillary nerve block. For the warming of ropivacaine, an air chamber (LD-918H5, lequip, Republic of Korea) was used, which was designed to maintain the temperature at $37^{\circ} \mathrm{C}$. We checked that ropivacaine ampoules were maintained at a temperature of $37^{\circ} \mathrm{C}$ when stored in the chamber for 20 minutes. The ropivacaine, equipment, syringes, and scalp vein needles used for the axillary nerve block were stored in this air chamber for more than two hours, before the start of the procedure.

During the axillary nerve block, the pulse at the axillary artery was palpated and the axillary artery was punctured using a scalp vein needle. Ropivacaine was injected four times into the area near the axillary nerve, through repeated artery perforations, with 5 or $10 \mathrm{ml}$ injected each time. After injection, the onset of the sensory and motor block was evaluated six times over a period of thirty minutes, at fiveminute intervals. Evaluation of the sensory and motor block was performed individually for the radial, ulnar, median, and musculocutaneous nerves, by a doctor who did not perform the axillary nerve block. Alcohol swab was used to evaluate the sensory nerve block. The cold sensation was compared between the anesthetized and non-anesthetized arm at the same regions innervated by individual nerves. The Hollmen scale was referred to with respect to the onset time of the sensory nerve 
block. The modified Hollmen scale was applied to increase the objectivity of the record, taking into consideration the time when the grade was 3 or higher for the onset time (Table 2) [11]. For the motor nerve block evaluation, the Hollmen scale was also applied, comparing the movement controlled by the same nerve in both arms (Table 3). The radial nerve was evaluated on the basis of abduction of the thumb and extension of the wrist, the ulnar and median nerves on the basis of the grasp, and the musculocutaneous nerve on the basis of arm flexion. The duration of analgesia was determined as the time from immediately after ropivacaine injection to the time when the patient first demanded injection of an analgesic after the end of operation.

Table 2. Hollmen Scale and Modified Hollmen Scale for Sensory Block

\begin{tabular}{|c|c|c|}
\hline & $\begin{array}{c}\text { Hollmen scale } \\
\text { (for sensory block) }\end{array}$ & $\begin{array}{l}\text { Modified Hollmen scale } \\
\text { (for sensory block) }\end{array}$ \\
\hline Grade 1 & Full sensation & Full sensation \\
\hline Grade 2 & Weak sensation* & Weak sensation \\
\hline Grade 3 & Recognized as light touch $^{\dagger}$ & Sensation under $30 \%^{\ddagger}$ \\
\hline Grade 4 & Loss of sensation & Recognized as light touch ${ }^{\S}$ \\
\hline
\end{tabular}

* Minimal grade 2: sensory block onset. ${ }^{\dagger}$ Grade 3 : complete block.

${ }^{\ddagger}$ Grade 3: sensory block onset. ${ }^{\S}$ Grade 4 : complete block.

Table 3. Hollmen Scale for Motor Block

\begin{tabular}{ll}
\hline & Hollmen scale (for motor block) \\
\hline Grade 1 & Normal motor function \\
Grade 2 & Weak motor function \\
Grade 3 & Very weak motor action* \\
Grade 4 & Complete loss of motor action ${ }^{\dagger}$ \\
\hline
\end{tabular}

*Muscle force under $30 \%$ : onset of block. ${ }^{\dagger}$ Complete block.

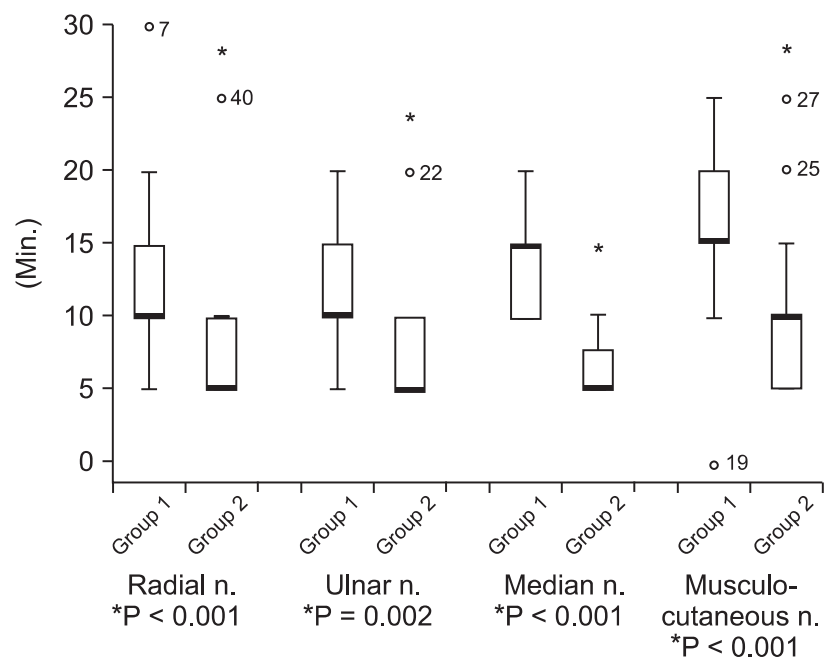

Fig. 1. The onset times of the sensory block in the radial, ulnar, median and musculocutaneous nerves were reduced in group 2 . $* \mathrm{P}<0.05$, compared with group 1 .
The SPSS software version 15.0 (SPSS Inc., Chicago, IL, USA) was used for statistical analysis. Data for statistical analysis showed abnormal distribution, except the duration of sensory nerve block. However, a non-parametric test (i.e. the MannWhitney U test) was performed, because the number of subjects in each group was less than 30 .

\section{Results}

The study was conducted in a total of 44 patients in Groups 1 and 2, with 22 patients in each group. There was no significant difference in the demographic characteristics between the two groups. Anesthesia failed in 2 patients for each group, and these four patients were excluded from the final analysis. No side effects of anesthesia were observed during the perioperative period.

The onset time of the sensory nerve block was significantly shorter in Group 2: by $43 \%$ in the radial nerve, by $38 \%$ in the ulnar nerve, by $55 \%$ in the medial nerve, and by $40 \%$ in the musculocutaneous nerve, compared to Group 1 (Fig. 1).

The onset time of the motor nerve block was also significantly

Table 4. Number of Blocked Nerves

\begin{tabular}{lcc}
\hline & Group 1 & Group 2 \\
\hline $5 \mathrm{~min}$ & $0 \pm 0$ & $0.6 \pm 0.9^{*}$ \\
$10 \mathrm{~min}$ & $0.2 \pm 0.5$ & $1.7 \pm 1.2^{*}$ \\
$15 \mathrm{~min}$ & $1.1 \pm 1.1$ & $2.6 \pm 1.0^{*}$ \\
$20 \mathrm{~min}$ & $1.8 \pm 1.1$ & $2.9 \pm 1.0^{*}$ \\
$25 \mathrm{~min}$ & $2.3 \pm 1.3$ & $3.1 \pm 0.9^{*}$ \\
$30 \mathrm{~min}$ & $2.9 \pm 0.9$ & $3.6 \pm 0.6^{*}$
\end{tabular}

Complete sensory block was defined as loss of cold sensation. Values are expressed as mean $\pm \mathrm{SD}$. ${ }^{*} \mathrm{P}<0.05$, compared with group 1 .

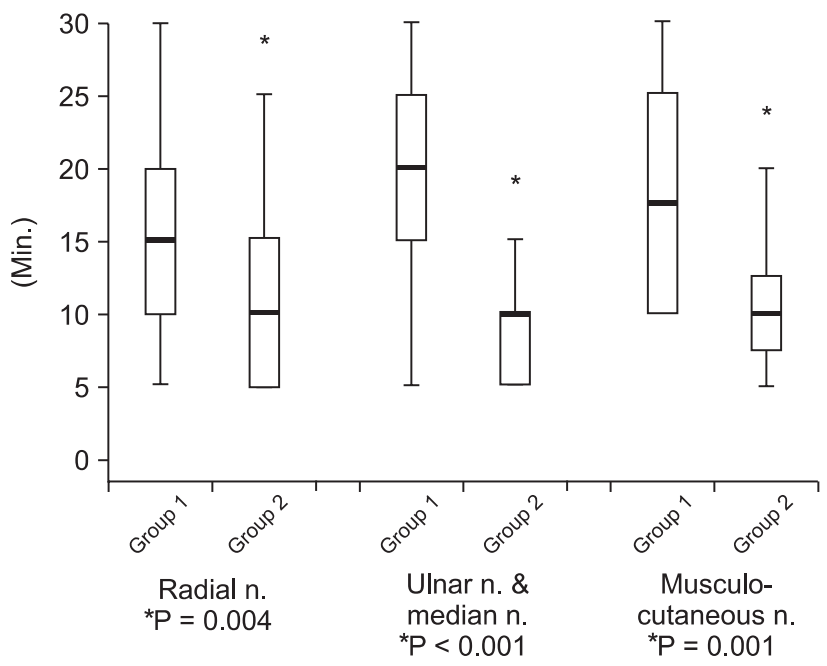

Fig. 2. The onset times of the sensory block in the radial, ulnar, median and musculocutaneous nerves were reduced in group 2 . ${ }^{*} \mathrm{P}<0.05$, compared with group 1. 
shorter in Group 2: by $37 \%$ in the radial nerve, by $59 \%$ in the ulnar and medial nerves, and by $42 \%$ in the musculocutaneous nerve, compared to Group 1 (Fig. 2).

In addition, the number of nerves blocked within 30 minutes after the anesthetic injection was significantly increased in Group 2, compared to Group 1 (Table 4).

The duration of analgesia was $606 \pm 186.7$ minutes (mean \pm standard deviation) in Group 1 and $738 \pm 245.5$ minutes in Group 2. Although the duration of analgesia was about two hours longer in Group 2, the difference was not statistically significant $(\mathrm{P}=0.056)$.

\section{Discussion}

In a short and simple operation at the upper limbs, regional brachial plexus block can be useful. For this purpose, the axillary block is a simple, safe, and reliable approach, and it can be applied to a wide extent in operations at the upper limbs $[12,13]$. Ropivacaine is a useful local anesthetic for brachial plexus block. Despite the relatively long onset time of regional block, ropivacaine is frequently chosen because of its relatively low toxicity to both cardiovascular and central nervous systems and its relatively long analgesic duration $[3,4]$.

Hydrochloric acid is included in most of the commonly used local anesthetic solutions, to increase the water solubility and to store the solution in a stable state, setting the $\mathrm{pH}$ between 4 and 6. Thus, the local anesthetic is mostly ionized in solution. If such a solution is directly used, the onset time of the regional nerve block is longer, because the number of non-ionized species that can pass through the cellular membrane is small. When bicarbonate is used as an adjunct together with ropivacaine, the onset time of the nerve block is shortened, as the number of hydrogen ions is decreased, whereas the number of non-ionized species is increased [1]. Such pH control plays a critical role with respect to the onset time of local anesthetics. This is the reason why opioids with a low $\mathrm{pH}$, such as fentanyl, can hardly be used as an adjunct to enhance the quality of anesthesia [14].

In addition to the use of bicarbonate, warming of the local anesthetic solutions has the effect of increasing the non-ionized local anesthetic species, since it increases the pKa value and the hydrogen ions are separated from the ionized local anesthetic species [8]. It has been reported that shortening of the onset time of the nerve block can be anticipated by an increase in the non-ionized local anesthetic species through warming $[9,10]$.

Several studies have investigated the effect of local anesthetics on various regional nerve blocks. Using bupivacaine and prilocaine in the brachial plexus block, Heath et al. [10] reported that the onset time of the nerve block was shortened by $30 \%$ and $50 \%$, respectively, by warming of the local anesthetics, depending on the nerves. Similarly, using ropivacaine in an epidural block, Liu et al. [15] also reported that the onset time of the epidural block was shortened by warming of the local anesthetic, and there were no side effects related to warming. These results can be explained as warming of the anesthetic decreased $\mathrm{pKa}$ value and increased permeability through the non-neural tissue to the nerve, which can also support our results $[16,17]$. However, the basic mechanism for the decrease in the onset time of the nerve block by warming of local anesthetics is still uncertain, and some results were contradictory. Thus, using lidocaine in a brachial plexus block, Chilvers [18] reported that the success ratio of the nerve block was lower in the group for which the local anesthetic was warmed and that there was no difference in the onset time between the two groups when the block was successful. In contrast, in our study, we found that the onset time of both the sensory block and motor block decreased by about $40-50 \%$ and the difference between groups was statistically significant.

Similar to our results, using bupivacaine for spinal anesthesia, Beardsworth and Lambert [19] reported that warming of the local anesthetic significantly extended the duration of the sensory nerve block and suggested that the result might have been caused by the decrease in the pKa value of the local anesthesia through warming, although the mechanism was not certain. In our study, the mean duration of analgesia was 606 minutes in Group 1 and 738 minutes in Group 2, indicating that the duration was about two hours longer in Group 2, although the difference was not statistically significant $(\mathrm{P}=0.056)$.

In the literature, there are reports of brachial plexus blocks where warmed bupivacaine, prilocaine, and lidocaine were used; however, to date, there was no study conducted with warmed ropivacaine. In this study, the brachial plexus was blocked with ropivacaine and our results show that the onset time of both the sensory block and motor block decreased by about $40-50 \%$ when the anesthetic was warmed.

In conclusion, this study showed that warming of ropivacaine to the body temperature may be clinically applied to shorten the onset time of the regional nerve block.

\section{References}

1. Murphy DB, McCartney CJ, Chan VW. Novel analgesic adjuncts for brachial plexus block: a systematic review. Anesth Analg 2000; 90: 1122-8.

2. Covino BG, Wildsmith JAW. Clinical pharmacology of local anesthetic agents. In: Neural blockade in clinical anesthesia and management of pain. 3rd ed. Edited by Cousins MJ, Bridenbaugh PO: Philadelphia, Lippincott-Raven Publishers. 1998, pp 97-128.

3. Knudsen K, Beckman Suurküla M, Blomberg S, Sjövall J, Edvardsson N. Central nervous and cardiovascular effects of i.v. infusions of ropivacaine, bupivacaine and placebo in volunteers. Br J Anaesth 1997; 78: 507-14. 
4. Hickey R, Candido KD, Ramamurthy S, Winnie AP, Blanchard J, Raza SM, et al. Brachial plexus block with a new local anaesthetic: 0.5 per cent ropivacaine. Can J Anaesth 1990; 37: 732-8.

5. Yang JH, Lee JJ, Hwang SM, Lim SY. The effect of fentanyl or epinephrine addition to ropivacaine in brachial plexus block. Korean J Anesthesiol 2004; 47: 655-9.

6. Kopacz DJ, Carpenter RL, Mackey DC. Effect of ropivacaine on cutaneous capillary blood flow in pigs. Anesthesiology 1989; 71: 6974.

7. Fulling PD, Peterfreund RA. Alkalinization and precipitation characteristics of $0.2 \%$ ropivacaine. Reg Anesth Pain Med 2000; 25 : 518-21.

8. Kamaya H, Hayes JJ Jr, Ueda I. Dissociation constants of local anesthetics and their temperature dependence. Anesth Analg 1983; 62: 1025-30.

9. Lee JA, Chung SJ, Han SB, Chung TH, Park CH. The effect on onset time of warming local anesthetic for caudal block. Korean J Anesthesiol 1997; 33: 1098-102.

10. Heath PJ, Brownlie GS, Herrick MJ. Latency of brachial plexus block. The effect on onset time of warming local anaesthetic solutions. Anaesthesia 1990; 45: 297-301.

11. Jadon A, Panigrahi MR, Parida SS, Chakraborty S, Agrawal PS, Panda A. Buprenorphine improves the efficacy of bupivacaine in nerve plexus block: A double blind randomized evaluation in subclavian perivascular brachial block. J Anaesth Clin Pharmacol 2009; 25: 207-10.
12. Tedore TR, YaDeau JT, Maalouf DB, Weiland AJ, Tong-Ngork S, Wukovits B, et al. Comparison of the transarterial axillary block and the ultrasound-guided infraclavicular block for upper extremity surgery: a prospective randomized trial. Reg Anesth Pain Med 2009; 34: 361-5.

13. King RS, Urquhart B, Urquhart B, Sharrock NE. Factors influencing the success of brachial plexus block. Reg Anesth Pain Med 1991; 16: 63.

14. Nishikawa K, Kanaya N, Nakayama M, Igarashi M, Tsunoda K, Namiki A. Fentanyl improves analgesia but prolongs the onset of axillary brachial plexus block by peripheral mechanism. Anesth Analg 2000; 91: 384-7.

15. Liu FC, Liou JT, Li AH, Day YJ, Yu HP. The effect of warmed ropivacaine to body temperature on epidural sensory block characteristics. J Clin Anesth 2010; 22: 110-4.

16. Mehta PM, Theriot E, Mehrotra D. Patel K, Kimball BG. A simple technique to make bupivacaine a rapid-acting epidural anesthetic. Reg Anesth 1987; 12: 135-8.

17. Lim ET, Chong KY, Singh B, Jong W. Use of warm local anaesthetic solution for caudal blocks. Anaesth Intensive Care 1992; 20: 453-5.

18. Chilvers CR. Warm local anaesthetic--effect on latency of onset of axillary brachial plexus block. Anaesth Intensive Care 1993; 21: 795-8.

19. Beardsworth D, Lambert DH. Warming $0.5 \%$ bupivacaine to 37 degrees C increases duration of spinal anesthesia. Reg Anesth 1989; 14: 199-202. 